\title{
ANÁLISE DA OCORRÊNCIA DE FEIÇÕES EROSIVAS LINEARES NA ÁREA DE PROTEÇÃO AMBIENTAL (APA) DO TIMBURI, PRESIDENTE PRUDENTE (SP)
}

Emanuela Sanches MOREIRA ${ }^{1}$

Leonardo da Silva THOMAZINI²

João Osvaldo Rodrigues NUNES3

Melina FUSHIMI4

Caio Augusto Marques dos SANTOS5

\begin{abstract}
Resumo
Os processos erosivos, resultados de alguns fenômenos físicos, em muitos casos atrelados as atividades humanas, geram perda de solos e criam um ambiente de vulnerabilidade, com perda da estabilidade e fertilidade do solo, afetando negativamente a economia e a sociedade. A fim de mitigar e, quando possível, prevenir os processos erosivos, faz-se necessário o conhecimento das características físicas e históricas da área. Assim, diante da homologação da primeira Área de Proteção Ambiental, localizada no Bairro do Timburi, município de Presidente Prudente (SP), este trabalho tem como objetivo analisar a ocorrência de processos erosivos lineares, e seus condicionantes geomorfológicos. Neste aspecto, foram elaborados diversos mapas temáticos, tendo como ponto central as formas de relevo, e a realização de trabalhos de campo para identificação das áreas mais vulneráveis ao desenvolvimento dos processos erosivos. Como resultados identificou-se que, das 78 feições erosivas lineares mapeadas, 48 (61,54\%) estão em vertentes côncavas; 33 (42,3\%) em declividade de 5-10\%; e 55 (70,51\%) relacionadas a áreas antrópicas agrícolas.
\end{abstract}

Palavras-chave: Geomorfologia; Uso da Terra; Área de Proteção Ambiental; Processos Erosivos; Vulnerabilidade Ambiental.

\footnotetext{
1 Graduanda em Geografia pela FCT/UNESP - Presidente Prudente. E-mail: manu_svm@hotmail.com

2 Pós-doutorando do Programa de Pós Graduação em Geografia da UNESP - Presidente Prudente. E-mail: 1.thomazini@unesp.br

3 Professor Adjunto Livre Docente do Departamento de Geografia da FCT/UNESP - Presidente Prudente. E-mail: joao.o.nunes@unesp.br

4 Professora Dra do Programa de Pós Graduação em Geografia, Natureza e Dinâmica do Espaço da Universidade Estadual do Maranhão (UEMA). E-mail: melinafushimi@yahoo.com.br

5 Professor Dr. Do Departamento de Geografia da Universidade Federal de Rondonópolis UFR. E-mail: kiomarques@hotmail.com
} 


\title{
ANALYSIS OF THE OCCURRENCE OF EROSIVE FEATURES IN THE ENVIRONMENTAL PROTECTION AREA (APA) OF TIMBURI, PRESIDENTE PRUDENTE (SP).
}

\begin{abstract}
The erosive processes, results of some physical phenomena, in many cases related to the human activities, cause soil loss and create an environmental vulnerability with loss of soil stability and fertility, negatively affecting the economy and the society. In order to mitigate and, when possible, to prevent the erosive processes, it is necessary, the knowledge of the physical and historical characteristics of the area. Therefore, in view of approval of the first Área de Proteção Ambiental, located in Bairro do Timburi, municipality of Presidente Prudente (SP), this assignment aimed to analyze the occurrence of erosion processes linear, and their geomorphological conditions. In this regard, several thematic maps were drawn up, having as a central point the forms of relief, and carrying out fieldwork to identify the areas most vulnerable to the development of erosion processes. As a result, it was identified that, of the 78 linear erosive features mapped, 48 (61.54\%) are in concave slopes; 33 (42.3\%) on a slope of 5$10 \%$; and $55(70.51 \%)$ related to agricultural anthropic areas.
\end{abstract}

Keywords: Geomorphology; Morphometry; Environmental Protection Area; Erosive Processes; Environmental Vulnerability.

\section{ANÁLISIS DE LA OCURRENCIA DE CARACTERÍSICAS EROSIVAS LINEALES EN EL ÁREA DE PROTECCIÓN AMBIENTAL (APA) DE TIMBURI, PRESIDENTE PRUDENTE (SP)}

\section{Resumen:}

Los procesos erosivos, procedentes de algunos fenómenos físicos, en muchos casos vinculados a actividades humanas, generan pérdida de suelos y crean un escenario de vulnerabilidad ambiental, con pérdida de estabilidad y fertilidad del suelo, que afecta negativamente a la economía y a la sociedad. Con la finalidad de mitigar y, en lo posible, prevenir los procesos erosivos, es necesario conocer las características físicas y históricas del área. Por lo tanto, dada la homologación del primer Área de Protección Ambiental, ubicado en el Bairro do Timburi, municipio de Presidente Prudente (SP), este trabajo tuvo como objetivo analizar la ocurrencia de procesos erosivos lineales y sus condiciones geomorfológicas. En este sentido, se elaboraron varios mapas temáticos, teniendo como punto central las formas de relevo y la realización del trabajo de campo para identificar las áreas más vulnerables al desarrollo de procesos erosivos. Como resultado, se identificó que, de las 78 características erosivas lineales mapeadas, 48 (61.54\%) están en pendientes cóncavas; 33 (42.3\%) en declividad de 5-10\%; y 55 (70.51\%) relacionados con áreas antrópicas agrícolas. Palabras clave: Geomorfología; Morfometria; Área de protección ambiental; Procesos erosivos; Vulnerabilidad ambiental. 


\section{INTRODUÇÃ̃}

O desenvolvimento dos processos erosivos, dentre diversos fatores, se relaciona a fenômenos físicos, sendo a erosão dos solos um fenômeno natural no qual ocorre a desagregação, remoção e transporte de partículas do solo pela ação combinada da gravidade, da água, do vento e de animais (BERTONI; LOMBARDI NETO, 1999), bem como também relacionados a composição química dos solos (NANDI, A.; LUFFMAN, 2012; XIA, J. et al., 2019). Em muitos casos, os processos erosivos não decorrem da ação humana, embora sejam responsáveis por inúmeros problemas sociais e econômicos, intensificando-os quanto menor for o poder aquisitivo daqueles que são atingidos.

Este fenômeno natural, que remonta às primitivas eras da existência da Terra, tem o equilíbrio dinâmico rompido a partir das intervenções das sociedades. O impacto das gotas de chuva em um terreno descoberto, e o resultante desprendimento das partículas do solo, são as principais causas da erosão hídrica. Dessa forma, a erosão consiste em um processo de desprendimento, arraste e deposição das partículas do solo causado pela água e pelo vento (BERTONI; LOMBARDI NETO, 1999).

De acordo com Guerra e Jorge (2013), os problemas relacionados a erosão iniciam-se quando as taxas de perda do solo ultrapassam os níveis naturais. Atualmente, pode-se atribuir o aumento dessas taxas às ações humanas praticadas no solo de maneira não cuidadosa. Quando muito explorado pelas atividades econômicas, como nos casos da agropecuária e da silvicultura, o solo acaba tendo sua capacidade produtiva comprometida não somente pela erosão, mas também pelo uso e manejo inadequados. Para um planejamento conservacionista, é necessário compreender os fatores que causam as perdas de solo e os que permitem reduzi-las (ROQUE et al., 2001).

Conforme Nunes et al. (2006), o problema da erosão deve-se ao fato de que a mesma ocorre de forma seletiva. Num primeiro momento, são carregadas as partículas mais finas, argila e matéria orgânica, juntamente com as partículas ativas do solo, responsáveis pelo transporte dos nutrientes, água e sais minerais às plantas. Uma vez que se estabeleça uma situação de perda dessas partículas, 
ocorrerá redução da fertilidade do solo, diminuição da capacidade produtiva e consequente comprometimento econômico e social.

Durante a precipitação, a água pode chegar ao solo direta ou indiretamente, quando interceptada pela cobertura vegetal. O impacto da queda da gota d'água causa o efeito splash, que apresenta maior intensidade quando atinge diretamente o solo e efeito reduzido quando atinge de maneira indireta. A água que infiltra aumenta o teor de umidade que, dependendo do volume da chuva, pode saturar o solo e eventualmente dar início ao escoamento superficial laminar, que tem início com o escoamento linear, responsável pelos processos erosivos iniciais de superfície (GUERRA; CUNHA, 1994; SANT'ANNA NETO, 1995).

Conforme esse escoamento se torna mais concentrado, tem-se o aprofundamento do canal de escoamento, que, com o tempo, formam os sulcos e as ravinas, frequentemente associados a um rápido aumento na quantidade de sedimentos transportados. Se não forem estabilizadas, as ravinas podem evoluir para o estado de voçorocas, que é uma forma erosiva de difícil contenção (GUERRA; SILVA; BOTELHO, 1999; WEILL; PIRES NETO, 2007).

Alguns fatores característicos da área podem influenciar na taxa de erosão e, de acordo com Bertoni e Lombardi Neto (1999), conhecê-los é de suma importância para os planejamentos conservacionistas. O tipo de solo é um fator importante, uma vez que, dependendo de suas características, ele pode apresentar mais ou menos suscetibilidade à erosão. Outro fator que também influencia a erosão é a cobertura vegetal, que normalmente auxilia em seu controle, devido à diminuição da energia que chega ao solo durante a chuva, mediante interceptação. Desta forma, contribui para migração do problema em regiões onde há chuvas de maior intensidade (WEILL; PIRES NETO, 2007). A cobertura vegetal também atua no aumento das taxas de infiltração do solo, atuando na recarga das águas subterrâneas (GUERRA; CUNHA, 1994).

Conforme Araújo, Almeida e Guerra (2013), a pressão excessiva dos animais sobre a cobertura vegetal pode ser um problema grave, sendo essa a situação da maioria das pastagens do Brasil. Um grande rebanho em uma área limitada pode ocasionar a competição pela pastagem, ultrapassando a produtividade natural do local, destruindo a vegetação e possibilitando a 
aceleração dos processos erosivos. A pecuária extensiva, particularmente em áreas de nascentes, pode ser a causa de relevantes impactos devido ao caminhamento do gado para dessedentação e à compactação pelo pisoteio (ZANZARINI; ROSOLEN, 2009).

O conhecimento das características físicas de uma área mais ou menos suscetível à erosão perpassa pelos levantamentos geomorfológicos (características morfométricas e morfológicas), que podem ser observados quando expressos em mapas de declividade e de compartimentos geomorfológicos, tendo, neste último, a integração entre os fatores naturais e antrópicos, possibilitando o "diagnóstico de situações bem como subsídios para o planejamento territorial em suas diversas escalas" (CARVALHO et al., 2001, p. $59)$.

As aplicações dos estudos geomorfológicos demonstram sua importância na compreensão da dinâmica do meio físico, em especial o relevo, que tem intercâmbio interacional direto com os meios hídrico, biológico, climático e socioeconômico.

Seguindo tais preceitos científicos, este artigo tem como objetivo analisar a contribuição da geomorfologia na compreensão de condicionantes de processos erosivos lineares em Áreas de Proteção Ambiental (APA's), tendo como objeto de estudo a APA do Timburi, localizada no município de Presidente Prudente - SP. A fim de alcançar o objetivo proposto, identificou-se as feições erosivas lineares por meio de imagens de satélite, relacionando-as com as cartas de compartimentos geomorfológicos, clinográfica e de uso e ocupação da terra, do objeto de estudo (FIGURA 1). 
Figura 1: Mapa de localização da Área de Proteção Ambiental de Uso Sustentável no Timburi, Presidente Prudente - SP.

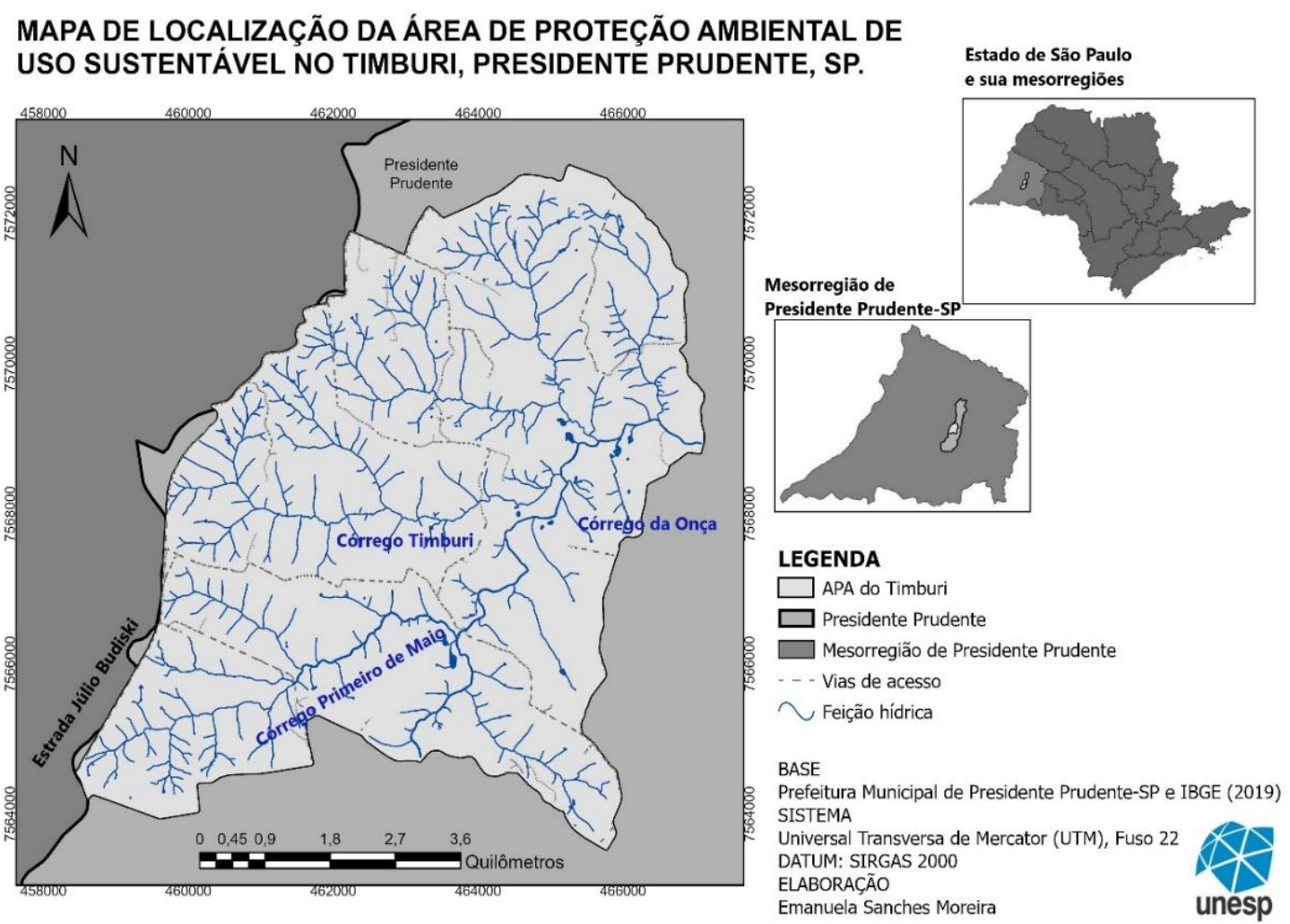

Fonte: Elaborado pelos autores.

Presidente Prudente apresenta, de acordo com IBGE (2019), extensão territorial de 560,637 km² e população estimada em 228.743 habitantes. Este município compõe a mesorregiões de Presidente Prudente, também conhecida como região do Pontal do Paranapanema, localizada no Oeste Paulista. Tal região tinha como cobertura original Floresta Estacional Semidecidual (Bioma Mata Atlântica) e cerrados. Entretanto, passou e vem passando por uma série de processos históricos e econômicos, que substituíram a vegetação nativa por pastagens e cultivos agrícolas, como podemos constatar em Queiroz Neto (2001).

Segundo Varcacel e Silva (1997), o desenvolvimento das atividades cafeeiras e da pecuária não considerou a conservação da vegetação nativa. Isso gerou grande degradação do ecossistema local, resultando hoje num grande número de processos erosivos, nascentes desprotegidas, cursos d'água assoreados, terrenos tecnogênicos e faixa muito estreita de mata ciliar ao longo dos rios e córregos. 
Tratando-se especificamente do município de Presidente Prudente, tivemos a produção de café, que condicionou a origem dos primeiros núcleos urbanos da cidade ao redor da linha de ferro. No entanto, com a crise de 1929, os cultivos foram substituídos pelo algodão, o que atraiu grandes indústrias de beneficiamento para a cidade, ocorrendo ainda a fase da menta, que era exportada para os Estados Unidos da América, a fim de fazer óleo para resfriar os motores dos aviões durante a Guerra.

Ao final da Segunda Guerra Mundial, aumentou-se o consumo de carne (SCHLESINGER, 2009), o que fez com que o Brasil investisse fortemente neste ramo até os dias atuais. Esse fator fez com que praticamente toda a zona rural de Presidente Prudente se transformasse em pastagens, o que degradou as matas nativas, não só pela necessidade do corte de árvores, mas também pelo intenso pisoteio do gado.

Dos seus mais de $560 \mathrm{~km}^{2}$, cerca de $544 \mathrm{~km}^{2}$ (97\%) são áreas rurais (IBGE Cidades, 2019), e é nesta porção que se encontram dois dos mais antigos bairros não urbanos do município. São eles o Timburi e o Primeiro de Maio, que tomaram bastante importância no ano de 2019, quando passaram a compor a Área de Proteção Ambiental de Uso Sustentável no Timburi (APA do Timburi). Esta é a primeira APA criada no município de Presidente Prudente, e só foi decretada após um conflituoso debate acerca da implantação de um aterro sanitário numa das fazendas ali localizadas, a Fazenda Santa Apolônia.

Segundo Donaton (2013), o território, que engloba ambos os bairros, possuí em torno de 82 propriedades rurais, somando 4.608,2 hectares. A economia é baseada na agropecuária, com predomínio de pastagens para a pecuária de corte e leiteira, intercalando com algumas porções de hortaliças, frutas e batata-doce. Quando houve a especulação para instalar o aterro sanitário na área, alguns moradores, unidos à servidores públicos da Faculdade de Ciências e Tecnologia da Universidade Estadual Paulista (FCT/UNESP), reivindicaram a proteção do local junto a prefeitura. Foi-se à audiência pública e, então, a conquista da criação da APA em maio de 2019.

A criação da APA se deu necessária para proteger a diversidade biótica e abiótica da região, uma vez que aquela área é dotada de mananciais com extrema relevância para o município. Entretanto, é vítima da degradação 
ambiental por meio de erosões hídricas, devido à retirada da cobertura vegetal nativa para as atividades agropecuárias. Também, a morfologia dos terrenos, com predomínio de colinas de topos estreitos e convexizados, com vertentes convexas e várias cabeceiras de drenagem com amplos anfiteatros, propiciam os processos erosivos lineares e laminares.

\section{METODOLOGIA}

Os procedimentos metodológicos adotados perpassaram por quatro etapas:

- Identificação visual das feições erosivas lineares na área de estudo através de imagens de satélite do software Google Earth-Pró;

- Quantificação das feições erosivas mapeadas;

- Elaboração dos mapas de compartimentos geomorfológicos, clinográfico e de uso e ocupação da terra;

- Sobreposição das feições erosivas identificadas nas cartas de compartimentos geomorfológicos, clinográfico e de uso e ocupação da terra;

- Trabalhos de campo na área de estudo para identificação e checagem complementar das feições erosivas.

Ainda, o levantamento bibliográfico nos ofereceu embasamento teórico acerca da relação entre a geomorfologia, o uso da terra e os processos erosivos. Tais contribuições teórico-metodológicas enriqueceram este artigo, o qual possui importante teor científico no âmbito da relação entre o desenvolvimento dos processos erosivos e a declividade da área de estudo.

Além disso, os trabalhos de campo possibilitaram uma maior coesão na caracterização do local, bem como na confecção dos mapas, os quais terão suas metodologias apresentadas a seguir.

\section{Carta clinográfica}

O mapa clinográfico da APA do Timburi foi elaborado no software $\operatorname{ArcGIS}^{\circledR}$, versão 10.5, a partir da base digital planoaltimétrica na escala 1:10.00o e curvas de nível com equidistâncias de 10 metros da Prefeitura Municipal de Presidente Prudente-SP. 
A princípio, criou-se uma estrutura de grade triangular TIN (Triangular Irregular Networks) por meio das ferramentas “Create TIN From Features” e “TIN to Raster". Em seguida, a opção "Face slope with graduated color ramp" foi adicionada. As classes de declividade definiram-se segundo Cunha (2001), realizando adaptações para as características ambientais da área de estudo (QUADRO 1).

Quadro 1: Adaptação das classes de declividade utilizadas por Cunha (2001) para a área de estudo.

\begin{tabular}{|c|c|}
\hline $\begin{array}{c}\text { Classes de declividade propostas por } \\
\text { Cunha (2001) }\end{array}$ & $\begin{array}{c}\text { Classes de declividade adaptadas para } \\
\text { a área de estudo }\end{array}$ \\
\hline$<5 \%$ & $\leq 5 \%$ \\
\hline $5 \mathrm{~F} 10 \%$ & $5 \mathrm{~F} 10 \%$ \\
\hline $10 \mathrm{~F} 20 \%$ & $10 \mathrm{~F} 15 \%$ \\
\hline $20 \mathrm{~F} 30 \%$ & $15 \mathrm{~F} 20 \%$ \\
$30 \mathrm{~F} 40 \%$ & $>20 \%$ \\
$\geq 40 \%$ & \\
\hline
\end{tabular}

Fonte: Cunha (2001). Elaboração: autores.

\section{Carta geomorfológica}

A carta geomorfológica foi espacializada no ArcGIS ${ }^{\circledR} 10.5$ com base no mapa geomorfológico do município de Presidente Prudente-SP na escala 1:25.00o elaborado por Nunes e Fushimi (2010), os quais realizaram a fotointerpretação de feições geomorfológicas de fotografias aéreas do ano de 1995. Posteriormente, trabalhos de campo foram feitos para verificar e atualizar as informações mapeadas. A legenda baseou-se em Tricart (1965), Verstappen e Zuidam (1975) e no mapa geomorfológico do perímetro urbano de Presidente Prudente-SP (NUNES et al., 2006). Ainda, os pontos cotados, as vias de acesso e os cursos d'água inseridos nos mapas foram disponibilizados pela Prefeitura Municipal de Presidente Prudente-SP e o limite municipal possui como referência o Instituto Brasileiro de Geografia e Estatística (IBGE, 2013).

As feições erosivas lineares (sulcos e ravinas), presentes nos documentos cartográficos, foram identificadas em imagens do Google Earth Pro ${ }^{\circledR}$, datadas de 2020, bem como em trabalhos de campo. Cabe ressaltar que, mediante a escala da carta apresentada, não foi possível categorizar as feições erosivas entre seus 
níveis, tais como sulcos, ravinas e voçorocas, optando em identificar apenas a ocorrência da erosão seja ela qual for.

\section{Carta de uso e ocupação da terra}

A carta de uso e ocupação da terra foi elaborada na versão Pro 2.5 do ArcGIS ${ }^{\circledR}$ na escala de 1:25.00o e teve como base a imagem de satélite Sentinel2, datada de 29 de novembro de 2019, com resolução de 10 metros. A princípio, foi realizado o recorte da área com a base disponibilizada pela Prefeitura de Presidente Prudente-SP e, então, criou-se uma classificação supervisionada a partir das ferramentas "Gerenciador da Amostra de Treinamento" e "Classificar".

Na primeira ferramenta, a partir da opção "Polígono", foram desenhadas várias amostras de cada classe definida. As classes foram escolhidas com base nos usos observados na imagem de satélite e confirmados em campo. Para análise da imagem foi levado em consideração a textura, a rugosidade e a tonalidade dos objetivos observados nas imagens. Então, agruparam-se as diferentes feições em três diferentes classes: áreas de vegetação natural, áreas antrópicas agrícolas e áreas descobertas. Essas classes, bem como suas cores, foram definidas de acordo com o Manual Técnico de Uso da Terra do IBGE (2013). Essa escolha visa padronizar analises dessa categoria, uma vez que o manual se mostra bastante completo e acessível.

Após a definição das amostras divididas em três classes, criou-se um arquivo shapefile para cada uma delas e então usou-se a ferramenta "Classificar", a qual classificou automaticamente o mapa. Por fim, os pixels foram generalizados, por meio das ferramentas "Ferramentas do Spatial Analyst", “Generalização" e "Filtro Predominante”, e o mapa foi finalizado com as devidas edições.

\section{ANÁLISE DOS RESULTADOS}

A análise dos resultados tem como ponto central e de articulação as diferentes dinâmicas de ocupação das formas de relevo da APA do Timburi 
A área da APA do Timburi é constituída por várias bacias hidrográficas, sendo as principais dos Córregos do Primeiro de Maio e do Timburi, sendo estes afluentes do Córrego da Onça.

Assim, quando se observa o mapa geomorfológico (FIGURA 2), identifica-se o predomínio das formas de vertentes convexas, seguidas pelas côncavas e, por último, as retilíneas, sendo estas marcantes nos fundos de vales.

Em relação aos compartimentos de relevo, conforme Nunes e Fushimi (2010), na APA do Timburi delimitou-se três compartimentos de relevo, que se associam com as seguintes formações geológicas e pedológicas:

1. Topos suavemente ondulados das colinas convexizadas, onde predominam solos desenvolvidos (associação Latossolos Vermelhos) ou solos rasos a desenvolvidos (associação Argissolos Vermelhos). Em alguns setores, têm-se solos rasos (associação Neossolos Regolíticos) e afloramento dos arenitos da Formação Adamantina (IPT, 1981);

2. Domínio das vertentes côncavas, convexas e retilíneas, com ocorrência de solos rasos a desenvolvidos (associação Argissolos Vermelhos) ou solos rasos (associação Neossolos Regolíticos), com frequente afloramento dos arenitos da Formação Adamantina;

3. Planícies aluviais e alvéolos, com a presença de solos hidromórficos (associação Planossolos e Gleissolos) e terraços fluviais com depósitos tecnogênicos (materiais de origem humana). Em alguns pontos, temse o afloramento dos arenitos da Formação Adamantina. 
Figura 2: Mapa Geomorfológico da Área de Proteção Ambiental de Uso Sustentável no Timburi, Presidente Prudente-SP.

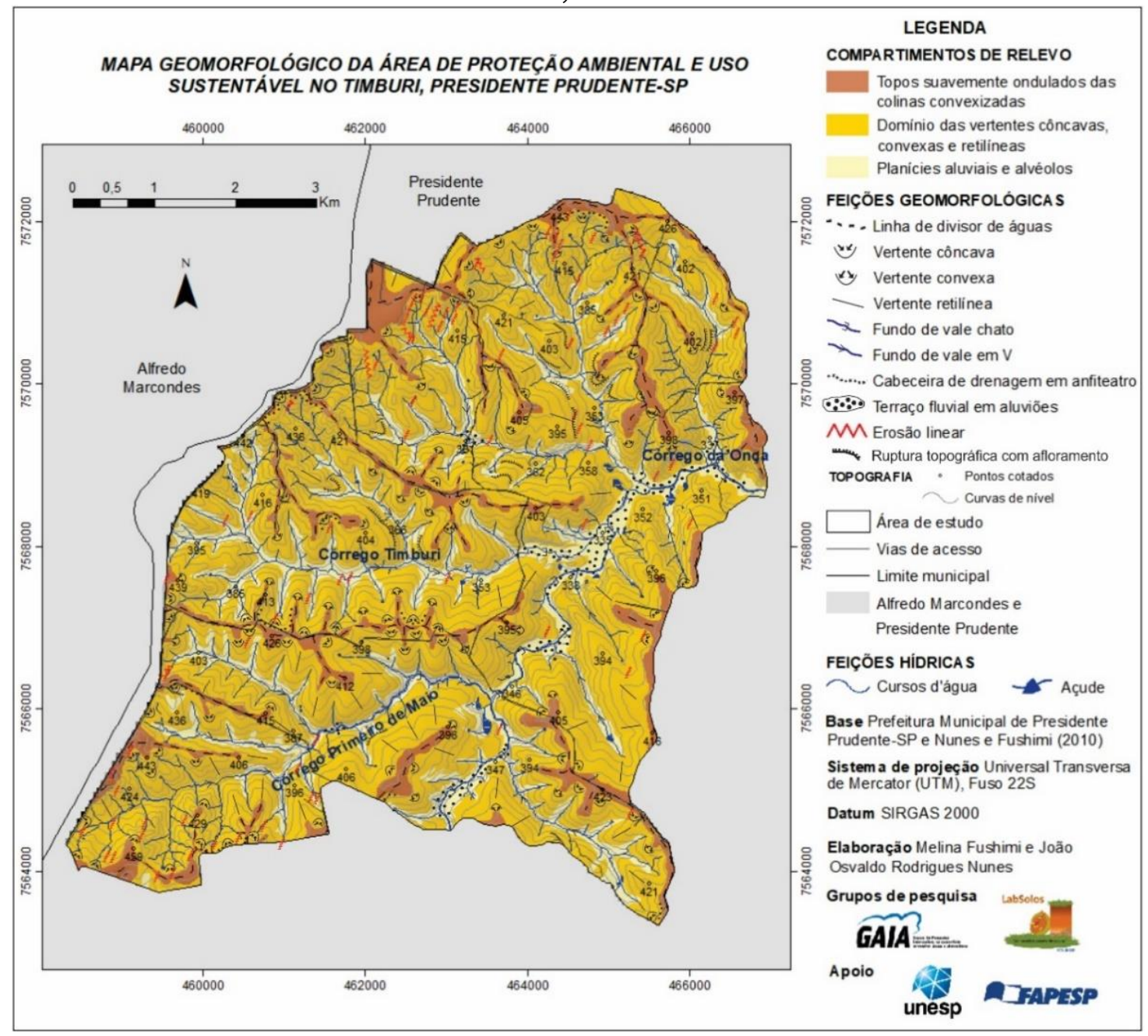

Fonte: Elaborado pelos autores.

De modo geral, apresenta rugosidade topográfica média, sendo de colinas com topos estreitos e predomínio de declividades acima de $20 \%$ e vertentes convexas, sendo que as côncavas são mais preponderantes nos setores de cabeceiras de drenagem em anfiteatros, vinculados aos canais de primeira ordem fluvial. Isto se reflete nas densidades de drenagem médias, com padrões dendríticos, dimensões interfluviais menores e morfologias de fundos vales encaixados em $\mathrm{V}$.

Estas características físicas vinculadas ao histórico de uso e ocupação da terra geraram um quadro de degradação ambiental em alguns setores da APA, materializada em intensos processos erosivos lineares. 
Neste aspecto, no Quadro 2, é possível observar a quantidade de feições erosivas lineares por curvatura da superfície. Verifica-se a predominância nas vertentes côncavas, já que condiciona o escoamento superficial de maneira concentrada.

Quadro 2: Feições erosivas lineares por forma da curvatura da superfície.

\begin{tabular}{|c|c|c|}
\hline Curvatura superfície & Quantidade de feições erosivas & $\%$ \\
\hline Côncavo & 48 & 61,54 \\
\hline Convexo & 28 & 35,89 \\
\hline Retilíneo & 2 & 2,57 \\
\hline
\end{tabular}

As formas convexas se relacionam com a declividade $\leq 5 \%$ (FIGURA 3 ), principalmente entre o topo e a vertente, marcando as rupturas abruptas de média vertente e o aumento da declividade. Em tal estrutura, característica da região, é comum a ocorrência de afloramentos do lençol freático, tornando o local mais vulnerável, ambientalmente, aos processos erosivos lineares.

Figura 3: Mapa Clinográfico da Área de Proteção Ambiental de Uso Sustentável no Timburi, Presidente Prudente-SP.

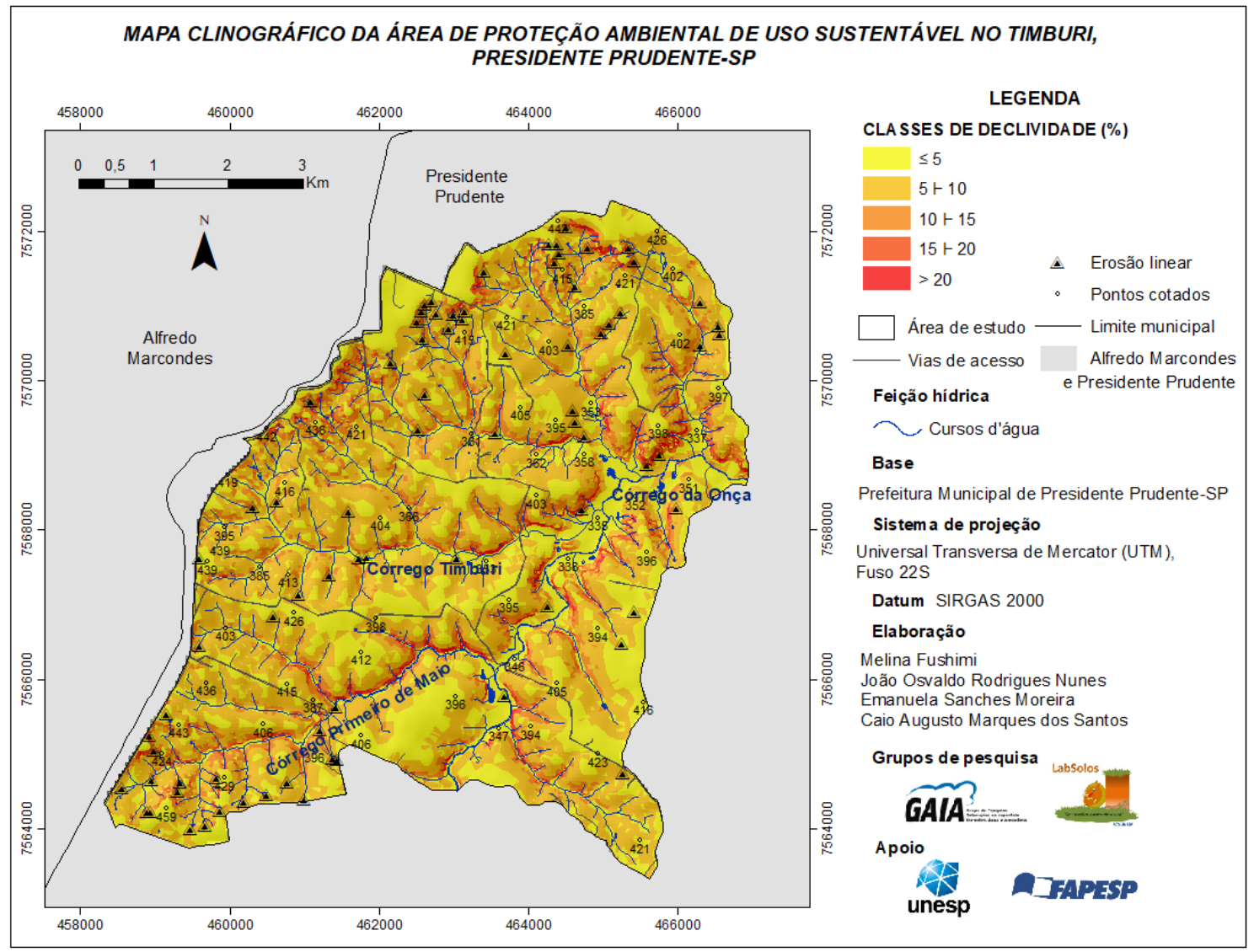

Fonte: Elaborado pelos autores. 
De acordo com o mapa clinográfico (FIGURA 3), observa-se a associação entre as áreas de baixa declividade com os topos convexizados e as planícies aluviais. As baixas vertentes, no entorno das planícies aluviais e alvéolos, possuem declividades que vão de $15 \%$ a acima de $20 \%$, demonstrando a presença de vertentes íngremes em direção aos fundos de vale. O Quadro 3 mostra a quantidade de feições erosivas por classe de declividade. É possível observar que as feições erosivas ocorrem, preferencialmente, nas vertentes côncavas entre 5 e $10 \%$.

Quadro 3: Feições erosivas lineares por classe de declividade.

\begin{tabular}{|c|c|c|}
\hline Mapa clinográfico & Quantidade de feições erosivas & $\%$ \\
\hline 5 & 14 & 17,95 \\
\hline $5-10$ & 33 & 42,3 \\
\hline $10-15$ & 22 & 28,2 \\
\hline $15-20$ & 8 & 10,26 \\
\hline 20 & 1 & 1,29 \\
\hline
\end{tabular}

A porção norte e nordeste da APA exibe declividades entre $15 \%$ a $20 \%$ e alguns pontos acima de 20\%, com grande concentração de focos erosivos. Percebe-se forte incidência de erosão linear, majoritariamente nas cabeceiras de drenagem em forma de anfiteatros. Caraterísticas também presentes no setor Sudoeste, onde encontra-se maiores declividades e porções de topos suavemente ondulados das colinas convexizadas.

Já no setor sul, com predomínio de declividades entre 5\% e 10\% (declividades de maior incidência erosões lineares), as erosões são escassas, assim como no setor Sudeste, com predomínio de planícies aluviais e alvéolos.

As declividades mais altas também se encontram nas margens do Córrego da Onça e do Primeiro de Maio, bem como no centro do Córrego Timburi. Ainda, podemos pontuar alguns focos erosivos nos percursos dos córregos e nas vertentes declivosas. A área central da APA, com exceção dos fundos de vales, manifesta declividades intermediárias, variando entre menor que $5 \%$ a $10 \%$, dispondo de poucos focos erosivos, os quais encontram-se esparsos nas vertentes predominantemente retilíneas.

A incidência dos focos erosivos nas nascentes dos córregos se explica pela alta declividade das vertentes relacionado ao uso da terra e falta de cobertura 
vegetal de porte (FIGURA 4), ocasionando fluxo concentrado do escoamento pluvial e consequente rupturas no solo desprotegido.

Figura 4: Mapa de cobertura e uso da terra da Área de Proteção Ambiental de Uso Sustentável no Timburi, Presidente Prudente-SP.

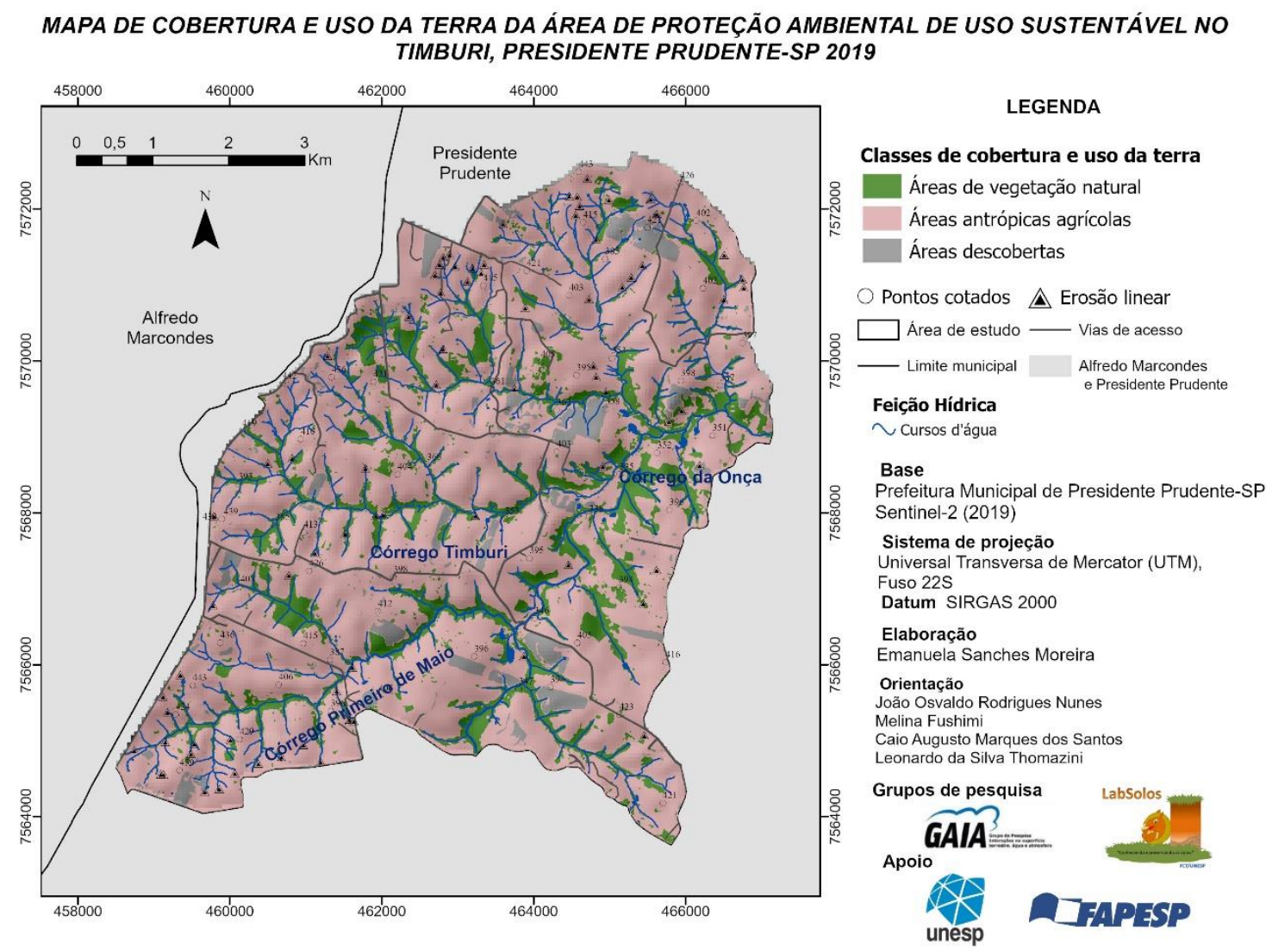

Fonte: Elaborado pelos autores.

O Quadro 4 mostra a quantidade de feições erosivas lineares por classe de uso e ocupação da terra. É claro e nítido como a alteração sucessiva do ambiente por diferentes práticas agropecuárias (pastagem para o gado de corte e leiteiro; plantio de batata-doce, milho, cana-de-açúcar, etc.), sem a aplicação de técnicas adequadas de manejo e conservação do solo geraram os processos erosivos.

Quadro 4: Feições erosivas lineares por classe de uso e ocupação da terra.

\begin{tabular}{|c|c|c|}
\hline Cobertura e uso da terra & Quantidade de feições erosivas & $\%$ \\
\hline Áreas de vegetação natural & 18 & 23,07 \\
\hline Áreas antrópicas agrícolas & 55 & 70,51 \\
\hline Áreas descobertas & 5 & 6,42 \\
\hline
\end{tabular}


A maior quantidade de processos erosivos em área de uso agrícolas decorre do processo de transformação da paisagem, tendo em vista que muitas das áreas descobertas precedem a implementação agrícola e quando esta se consolida, os processos erosivos, iniciados no período de dolo exposto, alcançam um estágio mais avançado e cartograficamente mapeáveis.

Nos médios cursos dos Córregos Timburi e Primeiro de Maio há a presença de focos erosivos que decorrem da força da água, unido à variação de declividade do leito. E, por fim, os focos encontrados nas vertentes, sobretudo retilíneas e convexas, também se dão devido à substituição de vegetação nativa por pastagens e pela declividade das médias vertentes (FUSHIMI, 2012).

Em tal processo, soma-se o mau uso do solo que, como observado em trabalho de campo, a área é caracterizada com o predomínio de pastagens para produção de gado de corte e leiteiro, com algumas faixas agrícolas esparsas. Então, além das vulnerabilidades físicas naturais, as atividades econômicas no local, como a criação de gado bovino, intensificam a formação de ravinas e voçorocas (FIGURA 5). Isso se dá devido ao intenso pisoteio dos animais que compacta o solo, diminuindo o poder de infiltração da água pluvial, e, ao mesmo tempo, aumentando o escoamento superficial, propiciando as feições erosivas (FUSHIMI, 2012).

Alguns setores da APA do Timburi possuem características físicas muito susceptíveis aos processos erosivos. As ações humanas desconhecendo as características naturais, e consequentemente, não respeitando suas limitações naturais, acabam intensificando os processos erosivos em diversos compartimentos de relevo, e gerando um quadro de degradação ambiental, como demonstra a Figura 5.

As rupturas topográficas com afloramento do aquífero freático suspenso, típicas da área de estudo e demonstradas nas imagens 2 e 6 (FIGURA 5), são identificadas nas vertentes convexas muito alteradas pelo uso e ocupação, cuja cobertura vegetal de gramínea se expressa mais rarefeita e menos densa. Podemos deduzir então, que as águas pluviais escoam das partes mais altas, passando por esse solo compactado e vegetação rarefeita, indo em direção aos fundos de vale. A energia do escoamento superficial sobre tal superfície gera as ravinas, que são um tipo de erosão linear intermediário. 
Figura 5: Localização dos focos erosivos nos diversos compartimentos de relevo da Área de Proteção Ambiental de Uso Sustentável no Timburi, Presidente Prudente-SP.

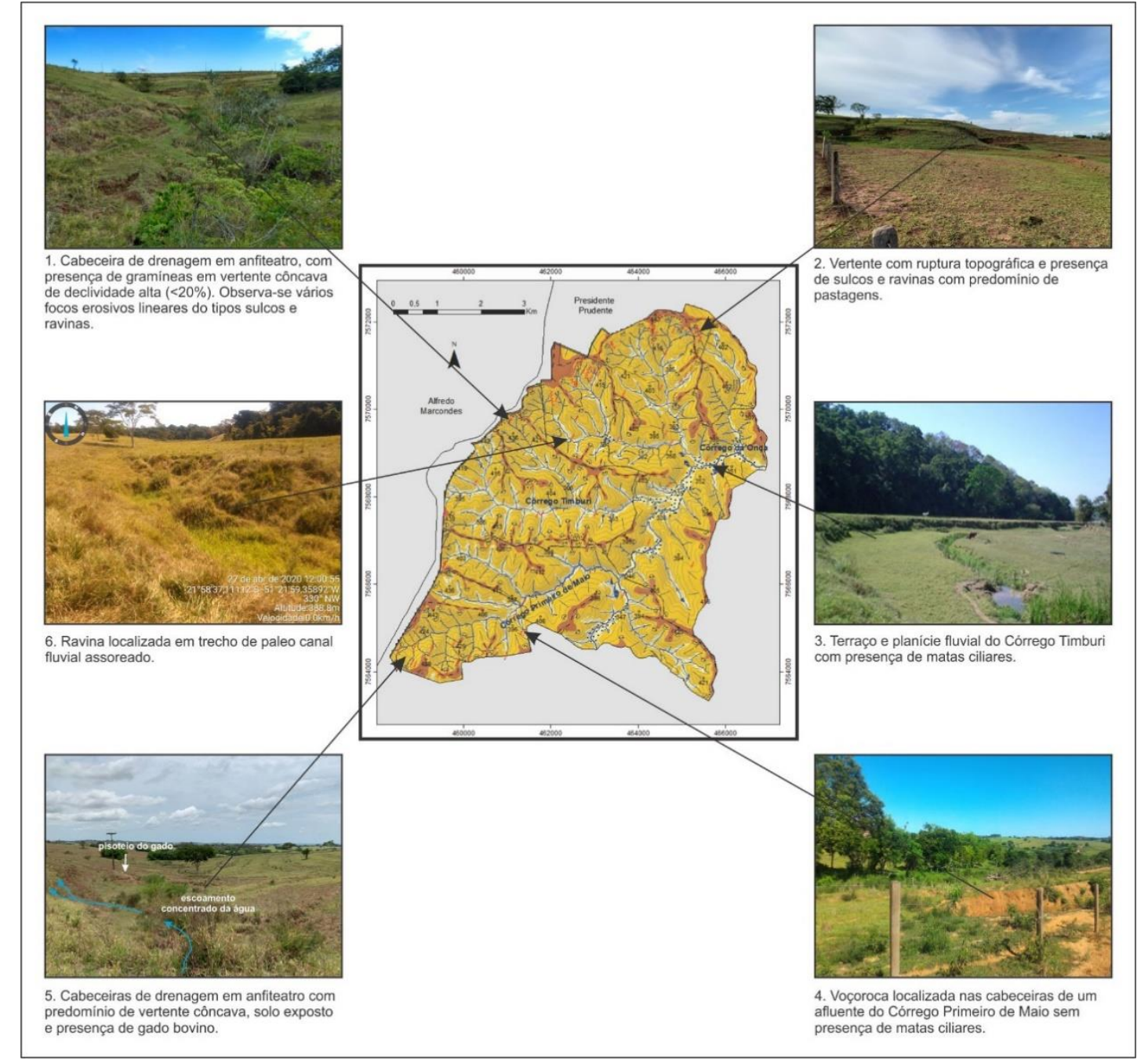

Foto: Autores, junho de 2020.

A retirada de vegetação das vertentes e o uso da terra para pastagens causam a quebra dos materiais constituintes e agregadores do solo (matéria orgânica e partículas coloidais), gerando a sedimentação que, além de formarem focos erosivos, são carregados e depositados nos fundos de vales, resultando no assoreamento dos córregos, uma vez que os sedimentos desprendidos das colinas e vertentes se deslocam para os cursos d'água e são depositados nas planícies aluviais, alteram as dinâmicas fluviais também nos terraços fluviais em aluviões (WEILI; PIRES NETO, 2007).

Dos três córregos localizados na APA do Timburi, o que mais sofre com esse processo é o Córrego da Onça, o qual possuí uma grande planície fluvial 
formada por sedimentos arenosos e argilosos inconsolidados (Atlas Ambiental Escolar de Presidente Prudente-SP, 2017). Este encontra-se margeado por vertentes mais declivosas (>20\%), o que propicia a deposição dos sedimentos nas planícies, além de receber águas de diversos afluentes localizados próximos aos topos de colinas.

Por fim, o Quadro 5 congrega o diagnóstico da ocorrência de feições erosivas lineares na área de estudo condicionadas pelas características das vertentes, pelo mapa de compartimentos geomorfológicos, da declividade e uso e ocupação da terra.

Quadro 5. Diagnóstico da ocorrência de feições erosivas lineares na Área de Proteção Ambiental do Timburi.

\begin{tabular}{|c|c|c|}
\hline Maiores ocorrências das feições erosivas & erosões & $\%$ \\
\hline Uso e ocupação - Áreas antrópicas agrícolas & 55 & 70,51 \\
\hline Curvatura da superfície - Côncava & 48 & 61,54 \\
\hline Declividade - 5\% a 10\% & 33 & 42,3 \\
\hline
\end{tabular}

Por conseguinte, observa-se que o conjunto de características e processos da área de estudo (áreas antrópicas agrícolas, vertente côncava e declividades entre 5 e 13\%) ajudam a indicar setores com alta vulnerabilidade ambiental a processos erosivos lineares na área de estudo. De acordo com Fushimi (2016), podemos compreender que:

“[...] a vulnerabilidade, sob a abordagem ambiental, está atrelada à fragilidade, isto é, à inter-relação dos constituintes da natureza. Todavia, se diferencia pela incorporação da ação da sociedade que altera as paisagens em detrimento dos seus interesses econômicos, sendo estes conduzidos pelo modo de produção capitalista." (FUSHIMI, 2016, p. 41).

Desta forma, o conjunto de características da área de estudo, em especial a declividade do terreno, configuram fatores que propiciam o aumento da vulnerabilidade ambiental. Contudo, é notório a interferência humana na intensificação dos processos degradativos do relevo. 


\section{CONSIDERAÇÕES FINAIS}

A partir do levantamento bibliográfico, dos trabalhos de campo e da confecção dos mapas pudemos promover o reconhecimento e a caracterização do objeto de estudo. Sendo assim, possível construir uma análise concisa entre a relação da geomorfologia do terreno e seus processos erosivos, bem como pontuamos as consequências da degradação ambiental, numa área que abriga inúmeras nascentes como a APA do Timburi.

O conjunto de características do relevo, encontrados no objeto de estudo do presente artigo, favorece a degradação ambiental, uma vez que o escoamento da água pluvial ocorre de forma intensa sobre as vertentes declivosas. Somamse a esse fator as ações antrópicas empregadas na área e o pisoteio do gado confinado, que compacta o solo exposto, tornando-o mais susceptível à deterioração.

Portanto, abordando todos esses aspectos, considera-se de extrema importância recuperar áreas degradadas, tendo em vista que esse processo acarreta uma série de desequilíbrios ambientais. A sedimentação das vertentes gera erosões que resultam no assoreamento dos rios e na exposição do lençol freático. Problemas dessa natureza são mais fáceis de serem prevenidos que revertidos.

Ao compreender a vulnerabilidade ambiental numa Área de Proteção Ambiental, a partir da contribuição da geomorfologia, evidencia-se a necessidade dos órgãos competentes e da comunidade local, em desenvolver estratégias de prevenção e contenção dos processos erosivos.

Especificamente na APA do Timburi, observamos que os processos erosivos ocorrem com maior ênfase nas áreas antrópicas com atividade agropecuária que ocupa 70,51\% da APA; nos setores de declividades com valores entre $5 \%$ a $10 \%$ e $10 \%$ a $15 \%$, ocupando $42,3 \%$ e $28,2 \%$, respectivamente da área da APA; geralmente próximo às nascentes dos cursos d'água, no norte, noroeste e sudoeste da APA, bem como em vertentes côncavas, formando 61,54\% da área. Esse fator é responsável por fragilizar a rede de drenagem local, o que aumenta a vulnerabilidade ambiental. 


\section{REFERÊNCIAS}

ARAUJO, G.H. de S.; ALMEIDA, J.R. de; GUERRA, A.T. Gestão ambiental de áreas degradadas. ed. 9. Rio de Janeiro: Bertrand Brasil, 2013.

BERTONI, J.; LOMBARDI NETO, F. Conservação do solo. ed. 4. Paulo: Ícone, 1999.

CARVALHO, P. F.; MENDES, I. A.; ARRUDA, E.; SIQUEIRA, M. C. Contribuição da Análise Geomorfológica para o Planejamento Urbano. In: CARVALHO, P. F.; BRAGA, R. (Org.). Perspectivas de Gestão Ambiental em Cidades Médias, LPM, Deplan - IGCE - Unesp: Rio Claro, 2001. p. 55-65

CUNHA, C. M. L. A cartografia do relevo no contexto da gestão ambiental. 2001. 128 p. Tese (Doutorado em Geociências e Meio Ambiente) Instituto de Geociências e Ciências Exatas, Universidade Estadual Paulista, Rio Claro, 2001.

DONATON, G. Estratégias de reprodução social e econômica em pequenas unidades produtivas rurais: o caso dos Bairros Rurais $1^{\circ}$ de Maio/Timburi e Ponte Alta/córrego da Onça no município de Presidente Prudente (SP). Monografia (bacharelado em Geografia). 2013. 112 f. Faculdade de Ciência e Tecnologia, Universidade Estadual Paulista, Presidente Prudente.

FUSHIMI, M. Vulnerabilidade Ambiental aos processos erosivos lineares nas áreas rurais do município de Presidente Prudente-SP. Dissertação (Mestrado em Geografia). 2012. 141 f. Faculdade de Ciências e Tecnologia, Universidade Estadual Paulista, Presidente Prudente.

FUSHIMI, M. Vulnerabilidade ambiental aos processos erosivos lineares de parte dos municípios de Marabá Paulista-SP e Presidente Epitácio-SP. Tese (Doutorado em Geografia). 2016. 199 f. Faculdade de Ciências e Tecnologia, Universidade Estadual Paulista, Presidente Prudente.

GUERRA, A.J.T.; CUNHA, S.B. da. Geomorfologia: uma atualização de bases e conceitos. Rio de Janeiro: Bertrand Brasil, 1994.

GUERRA, A.J.T.; JORGE, M. do C.O. Processos erosivos e recuperação de áreas degradadas. São Paulo: Oficina de Textos, 2013.

GUERRA, A.J.T.; SILVA, A.S. da; BOTELHO, R.G.M. Erosão e conservação dos solos: conceitos, temas e aplicações. Rio de Janeiro: Bertrand Brasil, 1999.

IBGE - INSTITUTO BRASILEIRO DE GEOGRAFIA E ESTATÍSTICA, 2019. Cidades. Disponível em: <https://cidades.ibge.gov.br/brasil/sp/presidenteprudente/panorama $>$. Acesso em: 05 jun. 2020.

IBGE - INSTITUTO BRASILEIRO DE GEOGRAFIA E ESTATÍSTICA, 2013. Geociências. Disponível em: <http://www.downloads.ibge.gov.br > Acesso em: 06 jan. 2020. 
IBGE - INSTITUTO BRASILEIRO DE GEOGRAFIA E ESTATÍSTICA, 2013. Biblioteca - Manual Técnico de Uso da Terra do IBGE (2013). Disponível em:

<https://biblioteca.ibge.gov.br/visualizacao/livros/liv81615.pdf>. Acesso em: 30 abr. 2020.

IPT - INSTITUTO DE PESQUISAS TECNOLÓGICAS DO ESTADO DE SÃO PAULO. Mapa Geológico do Estado de São Paulo: 1:500.000. São Paulo: IPT, vol. I, 1981 (Publicação IPT 1184).

NANDI, A.; LUFFMAN, I. Erosion Related Changes to Physicochemical Properties of Ultisols Distributed on Calcareous. Journal of Sustainable Development. Canadian Center of Science and Education, n. 8, v. 5, p.52-68, 2012.

NUNES, J. O. R.; FREIRE, R.; PERES, I. U. Mapa geomorfológico do perímetro urbano de Presidente Prudente-SP. In: SIMPÓSIO NACIONAL DE GEOMORFOLOGIA E REGIONAL CONFERENCE ON GEOMORPHOLOGY, 6., 2006, Goiânia. Anais [...] Goiânia: União da Geomorfologia Brasileira; International Association of Geomorphologists, 2006.

NUNES, J. O. R.; FUSHIMI, M. Mapeamento geomorfológico do município de Presidente Prudente-SP. In: SIMPÓSIO NACIONAL DE GEOMORFOLOGIA, 7., 2010, Recife. Anais [...] Recife: UFPE, 2010.

NUNES, J.O.R.; et al. Variações texturais dos Latossolos Vermelhos do Assentamento Rural Antônio Conselheiro-Mirante do Paranapanema/SP. Geografia em Atos, Unesp de Presidente Prudente, v. 1, p. 30-39, 2006.

PORTAL DO PROFESSOR. Atlas Ambiental Escolar de Presidente Prudente (2017). Disponível em:

<http://portaldoprofessor.fct.unesp.br:900o/topico/meio-fisicobiotico/>. Acesso em: 10 jun. 2020.

QUEIROZ NETO, J. P. de. EROSÃO DOS SOLOS TROPICAIS E SEU CONTROLE: O EXEMPLO DO ESTADO DE SÃO PAULO. In: Simpósio Nacional de Controle de Erosão, 7., Anais [...] Goiânia, p.1-11, 2001.

ROQUE, C.G.; CARVALHO, M.P.; PRADO, R.M. Fator Erosividade da chuva de Piraju (SP): distribuição, probabilidade de ocorrência, período de retorno e correlação com o coeficiente de chuva. R. Bras. Ci. Solo, n. 25, p.147-156, 2001

SANT'ANNA NETO, J. L. A erosividade das chuvas no estado de São Paulo. Revista do Departamento de Geografia, SAO PAULO: USP, v. 9, p.35-49, 1995 .

SCHLESINGER, S. O gado bovino no Brasil. 2009. Disponível em: <http://www.boell-latinoamerica.org/web/592.html>.

TRICART, J. Príncipes et Méthodes de la Geomorphologie. Paris: Masson \& Cie, 1965 . 
VARCACEL, R.; SILVA, Z. de S. A eficiência conservacionista de medidas derecuperação de áreas degradadas: proposta metodológica. Revista Floresta, Rio de Janeiro, v. 27, n. 12, p. 101-114, 1997.

VERSTAPPEN, H. T.; ZUIDAM, R. A. van. ITC System of geomorphological survay. Netherlands: Manuel ITC Textbook, vol.VII. 1975 .

WEILL, M. de A. M; PIRES NETO, A. G. Erosão e assoreamento. In: SANTOS, Rozely Ferreira dos (org.). Vulnerabilidade ambiental: desastres naturais ou fenômenos induzidos. Brasília: MMA, 2007. p.39-58.

XIA, J. et al. Granite residual soil properties in collapsing gullies of south China: spatial variations and effects on collapsing gully erosion. Catena, Elsevier, V.174, p. 469-477, 2019. Disponível em:

<https://www.sciencedirect.com/science/article/abs/pii/So341816218305022 $>$. Acesso em: 10ago. 2020

ZANZARINI, R.M.; ROSOLEN, V. Mata ciliar e nascente no cerrado brasileiro: análise e recuperação ambiental. In: ENCUENTRO DE GEÓGRAFOS DE AMÉRICA LATINA (EGAL), 12., Anais [...] Montevideo, 2009.

Recebido em 2 de maio de 2020

Aceito em 9 de julho de 2020 